\title{
BALANCE CONTROL IN ARTISTIC GYMNASTS AND ITS COMPARISON UNDER THREE TRAINING METHODS: A PILOT TRIAL
}

original paper

() Wroclaw University of Health and Sport Sciences

DOI: https://doi.org/10.5114/hm.2021.106167

\section{GUILLERMO MENDEZ-REBOLLEDO, YACAY OLCESE-FARIAS, DOMYNYK BROWN-VILLEGAS}

Escuela de Kinesiología, Facultad de Salud, Universidad Santo Tomás, Chile

\begin{abstract}
Purpose. Balance is a highly demanded motor ability in artistic gymnasts; however, it is unknown what type of training can improve this variable. The purpose was to determine if Star Excursion Balance Test (SEBT) and neuromuscular (NM) trainings are more effective than conventional artistic gymnastics training (CONV) for improving balance control in female artistic gymnasts.

Methods. Overall, 33 female artistic gymnasts were selected and randomly assigned to 3 training groups: CONV, SEBT, or NM. The Y-Balance Test evaluated balance control. ANOVA (group $\times$ time) with repeated measures was used to compare the effects of training.

Results. In the dominant lower limb, significant pre- and post-intervention differences were observed for SEBT training in the posteromedial direction $(p=0.0003 ; \%$ change $=13.4)$, as well as in NM in the anterior $(p=0.0001 ; \%$ change $=23.9)$, posteromedial $(p=0.0001 ; \%$ change $=23.1)$, and total index $(p=0.0001 ; \%$ change $=17.8)$ of the Y-Balance Test. Moreover, NM training presented significant differences compared with CONV $(p=0.0001 ; \%$ change $=14.0)$ and SEBT $(p=0.0001 ; \%$ change $=12.8)$ in the posteromedial direction; it also exhibited differences compared with CONV $(p=0.0392 ; \%$ change $=8.8)$ and SEBT $(p=0.0065$; $\%$ change $=11.3)$ in the total index.

Conclusions. NM training results in a significant improvement in balance control compared with CONV and SEBT training in female artistic gymnasts.
\end{abstract}

Key words: proprioceptive training, neuromuscular training, sport, athletes

\section{Introduction}

Artistic gymnastics is a sport characterized by highflying acrobatics and feats of strength [1]. However, it also requires other motor capacities such as flexibility, agility, and balance in the upper and lower limbs while performing motor skills (jumps, landing, push, and pull) in extreme joint positions [2]. Artistic gymnastics consists of 4 apparatuses for women (jump, uneven bars, balance beam, and floor exercises) [3]. The prevalence of injuries in artistic gymnastics is especially worrying, as younger athletes are being recruited, and they are in very early stages of motor and musculoskeletal development [4]. Specifically, in collegiate artistic gymnastics, an injury rate of 9.2-22.7 injuries per 1000 hours of exposure is reported, and about $70 \%$ of these injuries occur during disassembly from the apparatus [5]. Taking this information into account is important to understand the factors that could influence injuries and, subsequently, decreased sports performance.

The International Gymnastics Federation determines that the most difficult apparatus for women's gymnastics is the balance beam [3]. This apparatus is one of the most demanding disciplines in general female competition and requires the ability to balance to a high level, as it has an extremely small $(10 \mathrm{~cm})$ surface support with a height of $1.25 \mathrm{~m}$ and a length of $5 \mathrm{~m}$. In this context, a joint injury impairs the proprioceptive system, causing the musculoskeletal system

Correspondence address: Guillermo Mendez-Rebolledo, Escuela de Kinesiología, Facultad de Salud, Universidad Santo Tomás, Avenida Circunvalación \#1855, Talca, Chile, Código Postal: 3460000, e-mail: guillermomendezre@santotomas.cl

Received: May 30, 2020

Accepted for publication: January 14, 2021

Citation: Mendez-Rebolledo G, Olcese-Farias Y, Brown-Villegas D. Balance control in artistic gymnasts and its comparison under three training methods: a pilot trial. Hum Mov. 2022;23(2):56-64; doi: https://doi.org/10.5114/hm.2021.106167. 
to be more prone to repetitive injuries and decreased motor abilities, especially balance control during the performance of complex acrobatic elements [6].

The difficulty of the apparatus forces artistic gymnasts to demonstrate the ability to control balance during performance. The balance control represents the subject's ability to maintain the centre of mass within a support base and is considered a fundamental motor capacity for the execution of activities of daily living and sports [6-8]. Balance control requires constant postural adjustments owing to the displacement of the centre of mass, all of this through sensory and neuromuscular mechanisms that try to keep the centre of mass within the support base $[6,7,9]$. The balance control deficit mainly affects people with various pathologies, but less likely gymnasts as they usually have an adequate development of balance control since the centre of their trainings consists of exercises on balance beam. Therefore, determining a possible training focused on improving balance control in artistic gymnasts could be beneficial for optimizing athletic performance [5, 7].

Artistic gymnastics commonly bases its training on the development of flexibility, power, balance, lumbarpelvic strengthening (core), and strengthening of the upper and lower limbs [10]. In recent years, various sports have used training based on proprioception and neuromuscular responses to improve balance control. These interventions are training through the Star Excursion Balance Test (SEBT) [11] and neuromuscular (NM) training $[12,13]$. SEBT has been tested as a balance control evaluation method that involves loading one foot on the ground and trying the maximum reach with the opposite foot [11, 14], which challenges postural control, strength, range of motion, and proprio- ception of the subjects. This type of evaluation, and its use as training, is very similar to the technical performance that a gymnast must demonstrate within a competition. In turn, NM training is defined as a multi-component program [13] that integrates the development of motor skills (jumps, landings, running, etc.) with motor abilities (strength, endurance, flexibility, and balance) through plyometric and weight-bearing exercises [15-17]. Both methods - SEBT and NM training - attempt to improve balance control in various disciplines, but their effects on balance control in artistic gymnasts are unknown.

To our knowledge, there are few reports about balance control in artistic gymnasts evaluated through clinical or field tests. For this reason, the Y-Balance Test can be a tool applicable to artistic gymnasts, since it offers a simple, short-term, low-cost, and highly reliable evaluation $[18,19]$ and would also allow determining the effect of various trainings on balance control. In this context, the objective of this research was to establish if SEBT and NM training are more effective than conventional artistic gymnastics training (CONV) for improving balance control in female artistic gymnasts.

\section{Material and methods}

\section{Participants}

The study was a single-blind randomized controlled trial and followed the Consolidated Standards of Reporting Trials (CONSORT) recommendations. The research considered female participants aged 11-17 years belonging to the Escuela Chilena de Gimnasia (La Serena, Región de Coquimbo, Chile) (Table 1). The par-

Table 1. Baseline characteristics of the participants

\begin{tabular}{|c|c|c|c|c|c|}
\hline Characteristics & $\begin{array}{c}\mathrm{CONV}(n=11) \\
(\text { mean } \pm S D)\end{array}$ & $\begin{array}{c}\text { SEBT }(n=11) \\
(\text { mean } \pm S D)\end{array}$ & $\begin{array}{l}\mathrm{NM}(n=11) \\
(\text { mean } \pm S D)\end{array}$ & $p$ & $F$ \\
\hline Age category $11-12$ years $(n)$ & 3 & 2 & 3 & & \\
\hline Age category $13-15$ years $(n)$ & 6 & 8 & 7 & & \\
\hline Age category $16-17$ years $(n)$ & 2 & 1 & 1 & & \\
\hline Average training experience (years) & $3.1 \pm 0.7$ & $2.8 \pm 0.8$ & $2.9 \pm 1.8$ & 0.7580 & 0.2796 \\
\hline Average weekly training duration (h) & $15.6 \pm 2.1$ & $15.2 \pm 3.0$ & $15.2 \pm 3.4$ & 0.9455 & 0.5618 \\
\hline Age (years) & $13.0 \pm 1.5$ & $13.1 \pm 1.2$ & $13.7 \pm 1.6$ & 0.5532 & 0.6039 \\
\hline Weight (kg) & $50.3 \pm 8.4$ & $51.0 \pm 9.0$ & $50.3 \pm 6.8$ & 0.9713 & 0.0291 \\
\hline Height (m) & $1.54 \pm 0.05$ & $1.58 \pm 0.05$ & $1.56 \pm 0.05$ & 0.2680 & 1.3760 \\
\hline Body mass index $\left(\mathrm{kg} / \mathrm{m}^{2}\right)$ & $20.8 \pm 2.7$ & $20.1 \pm 2.5$ & $20.5 \pm 2.2$ & 0.8191 & 0.2009 \\
\hline Dominant lower limb length (cm) & $82.6 \pm 5.5$ & $84.4 \pm 3.6$ & $83.8 \pm 3.4$ & 0.6256 & 0.4765 \\
\hline Non-dominant lower limb length $(\mathrm{cm})$ & $82.6 \pm 5.6$ & $84.0 \pm 3.8$ & $83.6 \pm 3.1$ & 0.7239 & 0.3326 \\
\hline
\end{tabular}

CONV - conventional training, SEBT - Star Excursion Balance Test training, NM - neuromuscular training 


\section{HUMAN MOVEMENT}

G. Mendez-Rebolledo, Y. Olcese-Farias, D. Brown-Villegas, Balance training in artistic gymnasts

ticipants were selected through simple random sampling and subsequently assigned to 3 groups: CONV, SEBT, or NM training. The following inclusion criteria were considered: (a) being an artistic gymnast aged 11-17 years, (b) presenting a federated gymnast registry, and (c) having participated in a regional or national competition during the previous year. The artistic gymnasts were classified as sub-elite since they all participated in official international championships, namely South American or Pan American, and/or in national championships and obtained a classification between the $1^{\text {st }}$ and $10^{\text {th }}$ place of the general individual classification of their competitive category. For this research, the following exclusion criteria were applied: (a) consecutive training time less than 1 year, (b) 1 or no weekly training sessions, and (c) a lower limb injury within the previous 12 months or during the training period.

Although there is no research comparing the proposed training methods, previous reports show that a 15\% change for a direction of the Y-Balance Test demonstrates significant differences between artistic gymnasts of a low and high level of specialization [20]. For this reason, accepting an alpha risk of 0.05 and a beta risk of 0.2 in a bilateral contrast, 11 participants in each training group were required to detect a minimum difference of $15 \%$ between 2 groups, assuming a standard deviation of $10 \%$ and a loss to follow-up rate of $15 \%$.

\section{Y-Balance Test}

Balance control was evaluated with the Y-Balance Test Kit ${ }^{\mathrm{TM}}$ (Functional Movement Systems, Inc., Chatham, VA, USA) before and after the intervention. This device comprises a support platform to which 3 tubes are attached in the directions of anterior, posteromedial, and posterolateral reach. Each tube has markings in 5-mm increments. The first toe was positioned at the junction of the Y. Then, with the opposite foot, the participant had to push an 'indicator' along the tube trying to reach the greatest possible distance without putting the foot on the ground. The subjects were allowed to practise the test only twice in order to reduce the learning factor. At the end of the practice time, they were given a 2-minute break, and the dominant lower limb was evaluated in 3 directions (anterior, posterolateral, and posteromedial) [11, 18, 19]. In each direction, the procedure was repeated 3 times, and the average was recorded. Then, the participants rested for 5 minutes and repeated the procedure with the non-dominant lower limb. A trial was classified as invalid if the subject removed the hands from the hips, did not return to the starting position, did move the support foot (dominant), or loaded with the reach foot (non-dominant) [15, 21]. This abbreviated test is used in view of the limitations regarding the amount of time devoted to develop all directions of SEBT [18] and has demonstrated reliability and validity in predicting lower extremity injuries [19, 22].

The raw results of the Y-Balance Test were normalized. For this, the protocol described by Gribble et al. [23], who divided the distance reached by the length of the lower limb and then multiplied by 100 , was used. The length of the leg was measured from the anterior superior iliac spine to the most distal part of the medial malleolus. Additionally, a total index of the Y-Balance Test was calculated by dividing the sum of the 3 directions by 3 times the length of the evaluated lower limb and then multiplying by 100 [21]. Once the Y-Balance Test was carried out, the training period of the 3 groups began. At the end of the 8 weeks of training, a post-intervention Y-Balance Test was performed in each participant.

\section{Interventions}

The intervention time was 8 weeks, with 2 weekly training sessions [21]. Each training session lasted 20 minutes, and then the usual training was continued.

\section{Conventional training}

This training consisted of 8 minutes of jogging with joint mobility and 10-12 exercises of displacements in quadruped positions, rebounds on feet, and throws of legs in all directions, with 3 series of 12 repetitions per exercise. Twelve minutes were spent practising more specific gymnastic positions, such as split, straddle, lunge, bridge, and handstand, with 3 series of 15 repetitions.

\section{Training with Star Excursion Balance Test}

This training consisted of performing a warm-up of 6-8 minutes that included joint mobility and familiarizing each limb in the 8 directions of SEBT, intercepted at $45^{\circ}$ from one another. Then, the gymnasts executed SEBT, conducting 3 sets of 15 repetitions per direction (anterior, anterolateral, lateral, posterolateral, posterior, posteromedial, medial, and anteromedial) and lower limb, trying to reach the greatest 
distance with the leg without support in each of the directions, maintaining the posture for a second and then returning to the centre $[11,18,19]$.

\section{Neuromuscular training}

This training consisted of quadruped positions, coordination of body segments, muscular strengthening, and bipedal and unipedal positions on stable and unstable bases, which involved weight bearing or control of the lower limbs and trunk [13, 15-17]. The NM training was based on 8 different exercises per session applied to the lower limbs, with 3 series of 15 repetitions in the unipedal exercises and 3 series of 15-30 repetitions in the bipedal exercises, depending on their complexity. The workouts were distributed as follows:

- Weeks 1 and 2: coordination exercises on a stable surface, strengthening of the lower limb, bipedal and unipedal supports, with open eyes.

- Weeks 3 and 4: coordination exercises on a gymnastic mat, strengthening of the lower limb, supports and bipedal and unipedal jumps, with the eyes closed.

- Weeks 5 and 6: specific exercises for the lower limb with TheraBand, unipedal and bipedal exercises with open and closed eyes.

- Weeks 7 and 8: use of unstable surfaces (BOSU), supports and jumps, bipedal and unipedal exercises, with open and closed eyes.

When the artistic gymnasts finished one of the previous training sessions, they proceeded to continue their traditional training on the apparatus, with the exercises difficulty adjusted to the level of each gymnast. Two different apparatuses were trained daily, with the allocation of 30 minutes to each one (jump, asymmetric parallels, balance beam, and floor) defined weekly by the coach, and ending flexibility exercises performed for 15 minutes.

\section{Data analysis}

For all analyses, an alpha of 0.05 was considered and the GraphPad Prism software version 8.0.0 for Mac was used (GraphPad Software, San Diego, CA, USA). All variables were presented as mean and standard deviation. The Shapiro-Wilk test, Levene's test, and Mauchly's test were applied to evaluate the distribution, homogeneity of variance, and sphericity of the data, respectively. To establish significant differences between training groups (CONV, SEBT, and NM) and time (before and after intervention), a 2-way anal- ysis of variance (ANOVA) was used (group $\times$ time) with repeated measures. Post-hoc analysis was performed with Tukey's multiple comparison test. The percentage change between comparisons and the effect size $(E S)$ were calculated with Cohen's $d$, considering a trivial (0-0.19), small (0.20-0.49), medium (0.50-0.79), or large (0.80 or greater) result.

\section{Ethical approval}

The research related to human use has complied with all the relevant national regulations and institutional policies, has followed the tenets of the Declaration of Helsinki, and has been approved by the Ethics Scientific Committee of the Santo Tomás University (Chile) (Folio ID-149-19).

\section{Informed consent}

Informed consent has been obtained from all tutors and individuals included in this study and from the participants' legal guardians.

\section{Results}

All participants were included in the study analysis as there was $100 \%$ adherence to the training plan. The baseline characteristics of the sample can be seen in Table 1. The mean and standard deviation of the pre- and post-intervention variables are reported in Table 2. All the data presented a normal distribution, homogeneity of variance, and sphericity $(p>0.05)$.

In the dominant lower limb, the 2-way ANOVA with repeated measures implied significant interactions between factors (group $\times$ time) in the Y-Balance Test: anterior $(\mathrm{gl}=2 ; F=6.28 ; p=0.0076)$, posteromedial $(\mathrm{gl}=2 ; F=14.07 ; p=0.0002)$, and total index ( $\mathrm{gl}=2 ; F=6.60 ; p=0.0063)$. Post-hoc analysis can be seen in Tables 2 and 3. Specifically, the SEBT training group presented significant pre- and post-intervention differences in the posteromedial Y-Balance Test ( $p=$ $0.0003 ; E S=1.53 ; \%$ change $=13.4)$. Furthermore, the NM training group presented significant pre- and post-intervention differences in the anterior $(p=0.0001$; $E S=2.19 ; \%$ change $=23.9)$, posteromedial $(p=$ $0.0001 ; E S=2.64 ; \%$ change $=23.1)$, and total index $(p=0.0001 ; E S=2.11 ; \%$ change $=17.8)$ of the Y-Balance Test. In contrast, in the non-dominant lower limb, the 2-way ANOVA with repeated measures did not report significant interactions between factors (training group $\times$ time $)(p>0.05)$.

When comparing the effects of post-intervention training on the dominant lower limb, the post-hoc 
G. Mendez-Rebolledo, Y. Olcese-Farias, D. Brown-Villegas, Balance training in artistic gymnasts

Table 2. Y-Balance Test results for each training

\begin{tabular}{|c|c|c|c|c|c|c|c|c|c|}
\hline Y-Balance Test & Training & $\begin{array}{c}\text { Before } \\
(\text { mean } \pm S D)\end{array}$ & $\begin{array}{c}\text { After } \\
(\text { mean } \pm S D)\end{array}$ & $\begin{array}{c}\text { Mean } \\
\text { difference }\end{array}$ & \multicolumn{2}{|c|}{$95 \% \mathrm{CI}$} & $p$ & Cohen's $d$ & $\%$ change \\
\hline \multicolumn{10}{|c|}{ Dominant lower limb } \\
\hline \multirow{3}{*}{ Anterior (\%) } & CONV & $91.8 \pm 7.0$ & $95.4 \pm 10.8$ & -3.6 & -14.4 & 7.3 & 0.9021 & 0.39 & 3.9 \\
\hline & SEBT & $87.8 \pm 8.8$ & $96.1 \pm 7.5$ & -8.2 & -19.1 & 2.6 & 0.2092 & 1.01 & 9.4 \\
\hline & NM & $85.0 \pm 8.5$ & $105.3 \pm 10.0$ & -20.3 & -31.2 & -9.5 & 0.0001 & 2.19 & 23.9 \\
\hline \multirow{3}{*}{ Posteromedial (\%) } & CONV & $97.0 \pm 6.9$ & $102.4 \pm 9.6$ & -5.4 & -12.3 & 1.5 & 0.1855 & 0.64 & 5.6 \\
\hline & SEBT & $91.2 \pm 6.3$ & $103.4 \pm 9.3$ & -12.2 & -19.2 & -5.3 & 0.0003 & 1.53 & 13.4 \\
\hline & NM & $94.9 \pm 10.4$ & $116.8 \pm 5.5$ & -21.9 & -28.8 & -15.0 & 0.0001 & 2.64 & 23.1 \\
\hline \multirow{3}{*}{ Posterolateral (\%) } & CONV & $98.0 \pm 12.6$ & $97.0 \pm 17.4$ & 1.0 & -13.9 & 15.9 & 0.9999 & 0.07 & -1.0 \\
\hline & SEBT & $85.0 \pm 10.2$ & $88.6 \pm 13.0$ & -3.6 & -18.5 & 11.3 & 0.9711 & 0.31 & 4.2 \\
\hline & NM & $92.3 \pm 10.5$ & $98.7 \pm 10.6$ & -6.4 & -21.3 & 8.5 & 0.7503 & 0.61 & 7.0 \\
\hline \multirow{3}{*}{ Total index (\%) } & CONV & $95.1 \pm 7.1$ & $98.3 \pm 9.6$ & -2.6 & -11.0 & 5.7 & 0.9136 & 0.31 & 2.8 \\
\hline & SEBT & $88.0 \pm 5.7$ & $96.0 \pm 9.1$ & -8.0 & -16.4 & 0.3 & 0.0636 & 1.05 & 9.1 \\
\hline & $\mathrm{NM}$ & $90.7 \pm 8.6$ & $106.9 \pm 6.6$ & -16.2 & -24.5 & -7.9 & 0.0001 & 2.11 & 17.8 \\
\hline \multicolumn{10}{|c|}{ Non-dominant lower limb } \\
\hline \multirow{3}{*}{ Anterior (\%) } & CONV & $90.4 \pm 8.7$ & $100.9 \pm 12.2$ & -10.5 & -21.3 & 0.3 & 0.0607 & 1.00 & 11.6 \\
\hline & SEBT & $85.2 \pm 3.5$ & $94.1 \pm 13.8$ & -8.9 & -19.7 & 1.9 & 0.1465 & 0.88 & 10.4 \\
\hline & NM & $87.7 \pm 9.5$ & $98.2 \pm 13.5$ & -10.5 & -21.3 & 0.3 & 0.0607 & 0.90 & 11.9 \\
\hline \multirow{3}{*}{ Posteromedial (\%) } & CONV & $103.5 \pm 15.7$ & $110.6 \pm 15.8$ & -7.1 & -22.7 & 8.5 & 0.7099 & 0.46 & 6.9 \\
\hline & SEBT & $92.4 \pm 8.6$ & $104.4 \pm 12.7$ & -12.1 & -27.7 & 3.6 & 0.1937 & 1.10 & 13.1 \\
\hline & NM & $94.6 \pm 8.3$ & $114.7 \pm 15.1$ & -20.1 & -35.7 & -4.4 & 0.0072 & 1.65 & 21.2 \\
\hline \multirow{3}{*}{ Posterolateral (\%) } & CONV & $98.4 \pm 10.2$ & $94.5 \pm 12.4$ & 3.8 & -7.4 & 15.1 & 0.8868 & 0.34 & -3.9 \\
\hline & SEBT & $89.9 \pm 10.1$ & $91.2 \pm 13.0$ & -1.3 & -12.53 & 10.1 & 0.9991 & 0.11 & 1.4 \\
\hline & NM & $91.5 \pm 9.2$ & $100.6 \pm 11.6$ & -9.1 & -20.3 & 2.2 & 0.1596 & 0.87 & 9.9 \\
\hline \multirow{3}{*}{ Total index (\%) } & $\mathrm{CONV}$ & $97.1 \pm 9.6$ & $102.0 \pm 11.9$ & -4.7 & -15.0 & 5.8 & 0.7382 & 0.42 & 4.7 \\
\hline & SEBT & $89.1 \pm 5.7$ & $96.6 \pm 11.0$ & -7.4 & -17.8 & 3.0 & 0.2650 & 0.85 & 8.3 \\
\hline & NM & $91.3 \pm 6.8$ & $104.5 \pm 11.6$ & -13.2 & -23.6 & -2.8 & 0.0080 & 1.39 & 14.5 \\
\hline
\end{tabular}

CONV - conventional training, SEBT - Star Excursion Balance Test training, NM - neuromuscular training

The effect size is represented by Cohen's $d$.

analysis showed significant differences between NM training and CONV $(p=0.0001 ; E S=1.82 ; \%$ change $=$ $14.0)$ and SEBT $(p=0.0001 ; E S=1.74 ; \%$ change $=$ $12.8)$ in the posteromedial direction of the Y-Balance Test (Figure 1). Similarly, NM training presented significant differences compared with CONV ( $p=0.0392$; $E S=1.05 ; \%$ change $=8.8)$ and SEBT $(p=0.0065$; $E S=1.36$; \% change $=11.3)$ in the total index of the Y-Balance Test (Figure 1).

\section{Discussion}

The purpose of this study was to compare the effects of CONV, SEBT, and NM training on balance control in female artistic gymnasts. The main result was that when comparing the post-intervention effects on the dominant lower limb, it was observed that the NM training generated significant improvement in the balance control in the posteromedial direction of $14 \%$ in relation to $\mathrm{CONV}$, and the same NM training presented a $12.8 \%$ change over the SEBT training. In addition, in relation to the total index of the dominant lower limb, the NM training caused a change of $8.8 \%$ in relation to CONV, and a change of $11.3 \%$ compared with the SEBT training. In this way, NM training is the method that produces the best results in artistic gymnasts' balance control evaluated with the Y-Balance Test. To the best of our 
Table 3. Dominant lower limb results of the Y-Balance Test between trainings before and after intervention

\begin{tabular}{|c|c|c|c|c|c|c|c|}
\hline \multirow{2}{*}{ Y-Balance Test } & \multirow{2}{*}{$\begin{array}{c}\text { Comparison } \\
\text { Pre CONV vs. Pre SEBT }\end{array}$} & \multirow{2}{*}{$\begin{array}{c}\begin{array}{c}\text { Mean } \\
\text { difference }\end{array} \\
4.0\end{array}$} & \multicolumn{2}{|c|}{$95 \% \mathrm{CI}$} & \multirow{2}{*}{$\begin{array}{c}p \\
0.8526\end{array}$} & \multirow{2}{*}{$\begin{array}{c}\text { Cohen's } d \\
0.50\end{array}$} & \multirow{2}{*}{$\begin{array}{c}\% \text { change } \\
-4.3\end{array}$} \\
\hline & & & -6.9 & 14.8 & & & \\
\hline \multirow{5}{*}{ Anterior (\%) } & Pre CONV vs. Pre NM & 6.8 & -4.0 & 17.7 & 0.3874 & 0.88 & -7.4 \\
\hline & Pre SEBT vs. Pre NM & 2.8 & -8.0 & 13.7 & 0.9593 & 0.33 & -3.2 \\
\hline & Post CONV vs. Post SEBT & -0.7 & -11.5 & 10.2 & 0.9999 & 0.07 & 0.7 \\
\hline & Post CONV vs. Post NM & -9.9 & -20.8 & 0.9 & 0.0850 & 0.95 & 10.4 \\
\hline & Post SEBT vs. Post NM & -9.2 & -20.1 & 1.6 & 0.1236 & 1.05 & 9.6 \\
\hline \multirow{6}{*}{ Posteromedial (\%) } & Pre CONV vs. Pre SEBT & 5.8 & -1.1 & 12.7 & 0.1355 & 0.88 & -6.0 \\
\hline & Pre CONV vs. Pre NM & 2.2 & -4.8 & 9.1 & 0.9173 & 0.25 & -2.2 \\
\hline & Pre SEBT vs. Pre NM & -3.6 & -10.6 & 3.3 & 0.5805 & 0.42 & 4.0 \\
\hline & Post CONV vs. Post SEBT & -1.0 & -8.0 & 5.9 & 0.9970 & 0.11 & 1.0 \\
\hline & Post CONV vs. Post NM & -14.3 & -21.2 & -7.4 & 0.0001 & 1.82 & 14.0 \\
\hline & Post SEBT vs. Post NM & -13.3 & -20.2 & -6.3 & 0.0001 & 1.74 & 12.8 \\
\hline \multirow{6}{*}{ Posterolateral (\%) } & Pre CONV vs. Pre SEBT & 8.5 & -2.8 & 19.7 & 0.2157 & 1.13 & -13.2 \\
\hline & Pre CONV vs. Pre NM & 6.8 & -4.4 & 18.1 & 0.4251 & 0.49 & -5.8 \\
\hline & Pre SEBT vs. Pre NM & -1.6 & -12.8 & 9.6 & 0.9972 & 0.70 & 8.6 \\
\hline & Post CONV vs. Post SEBT & 3.4 & -7.9 & 14.6 & 0.9320 & 0.55 & -8.6 \\
\hline & Post CONV vs. Post NM & -6.1 & -17.3 & 5.2 & 0.5463 & 0.12 & 1.8 \\
\hline & Post SEBT vs. Post NM & -9.5 & -20.7 & 1.8 & 0.1335 & 0.85 & 11.4 \\
\hline \multirow{6}{*}{ Total index (\%) } & Pre CONV vs. Pre SEBT & 7.6 & -0.8 & 15.9 & 0.0879 & 1.18 & -7.9 \\
\hline & Pre CONV vs. Pre NM & 4.9 & -3.5 & 13.2 & 0.4628 & 0.62 & -5.1 \\
\hline & Pre SEBT vs. Pre NM & -2.7 & -11.0 & 5.6 & 0.9067 & 0.37 & 3.1 \\
\hline & Post CONV vs. Post SEBT & 2.2 & -6.1 & 10.6 & 0.9578 & 0.24 & -2.2 \\
\hline & Post CONV vs. Post NM & -8.7 & -17.0 & -0.3 & 0.0392 & 1.05 & 8.8 \\
\hline & Post SEBT vs. Post NM & -10.9 & -19.2 & -2.5 & 0.0065 & 1.36 & 11.3 \\
\hline
\end{tabular}

CONV - conventional training, SEBT - Star Excursion Balance Test training, NM - neuromuscular training The effect size is represented by Cohen's $d$.

knowledge, there are no previous studies comparing training methods through balance control in artistic gymnasts only; generally, the studies were carried out in other sports or in adult patients with various pathologies [7, 15, 21, 24, 25].

It is common to find in the literature research comparing gymnasts with other athletes or a sedentary population, concluding that artistic gymnastics training stimulates the development of balance control and allows an almost perfect stability in relation to other disciplines [26-28]. Currently, an improvement in balance control has been demonstrated through NM training lasting 6-8 weeks, in sessions conducted 3-5 times a week, with an average time of 20 minutes per session, in different athlete and nonathlete populations $[13,15,17]$. Physiologically, the nervous system is in charge of using the information from somatosensory mechanoreceptors [12], causing the skin, joints, ligaments, tendons, and muscles to provide sensory input to the central nervous system to generate a neuromuscular response and thus stabilize the joints [16]. Biomechanically, as the balance control difficulty increases, postural strategies more proximal to the ankle are requested, generating postural adjustments that continually help control balance [29]. In this sense, the inverted pendulum theory is the first to help the sagittal plane to create a compensatory response, locating its axis of rotation at the ankle joint [30]. Also, in the frontal plane, the hip weight change strategy controls the mediolateral balance, transferring the weight of the body from one leg to the other [30,31]. It could be deduced that the significant improvement observed in NM and SEBT training could be due to a greater request for postural control strategies, described above, in each training session. In this way, these settings resulted in significant improvements in the balance control of artistic gymnasts by training in the different planes of movement and requesting a greater number of 


\section{HUMAN MOVEMENT}

G. Mendez-Rebolledo, Y. Olcese-Farias, D. Brown-Villegas, Balance training in artistic gymnasts

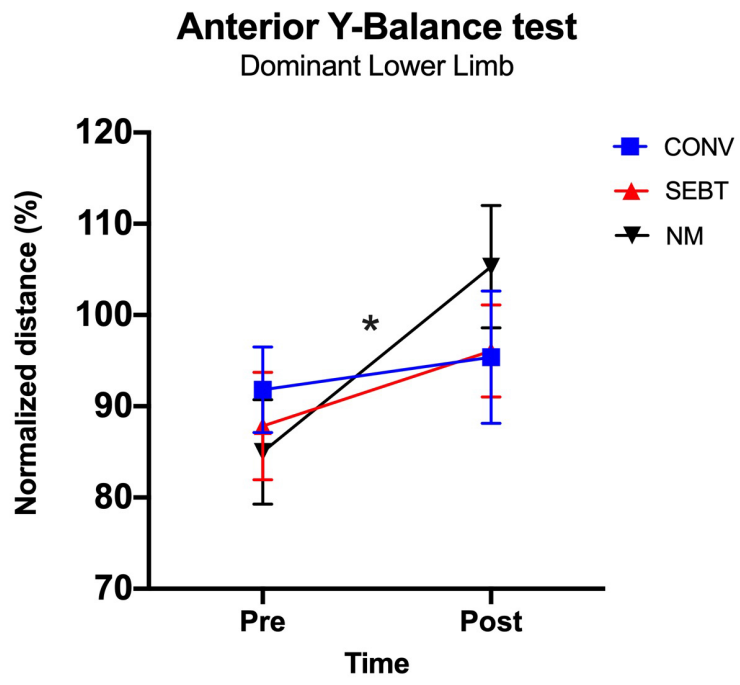

Posterolateral Y-Balance test Dominant Lower Limb

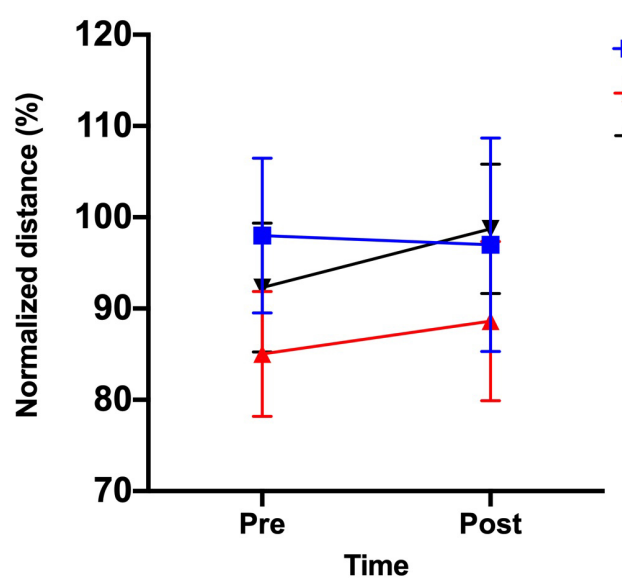

Posteromedial Y-Balance test Dominant Lower Limb

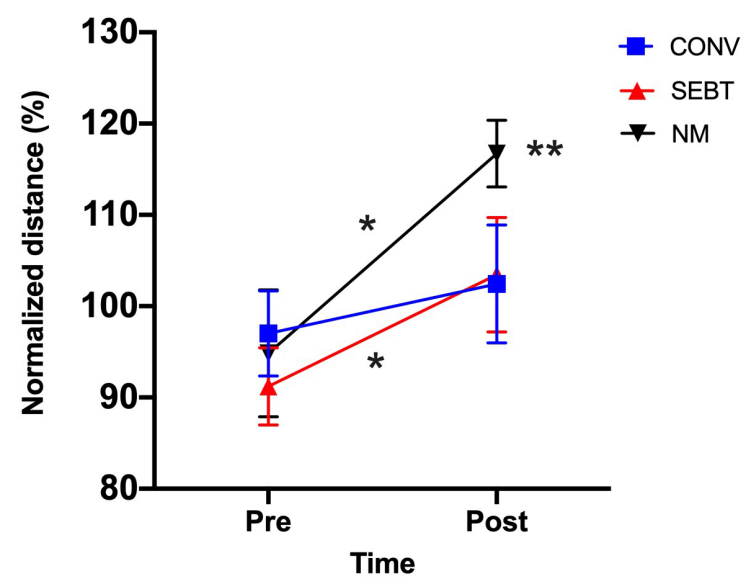

Total Index Y-Balance test Dominant lower limb

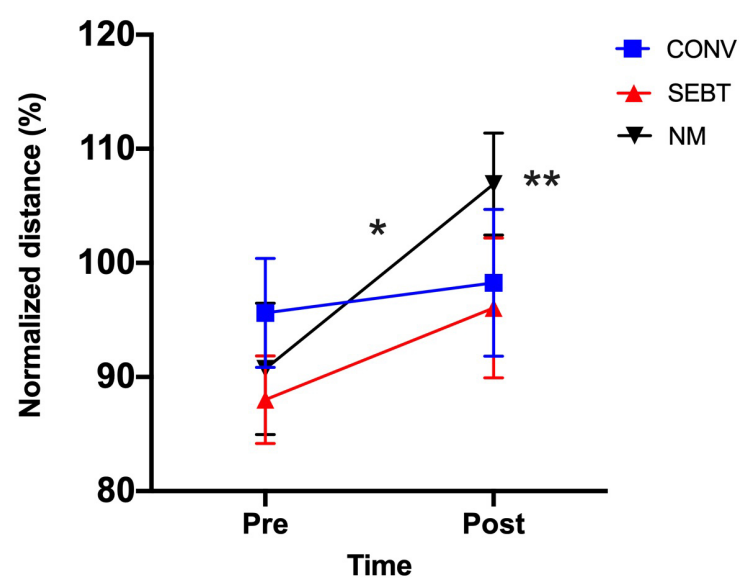

CONV - conventional training, SEBT - Star Excursion Balance Test training, NM - neuromuscular training

${ }^{*}$ significant differences between pre- and post-intervention times by training $(p<0.05)$

${ }^{* *}$ significant differences between trainings in the post-intervention time $(p<0.05)$

Figure 1. Comparisons between trainings in the pre- and post-intervention times

neuromuscular responses to the demands of balance control.

Michalski Peres et al. [32] showed that an NM training program applied in volleyball players was effective in increasing the balance control in both lower limbs. In the same context, Vitale et al. [33] applied the Y-Balance Test before and after intervention with an NM training in skiers, showing that the experimental group achieved positive effects in the posteromedial and posterolateral directions, as well as in the total percentage of the Y-Balance Test. As in the team sports noted above, our research has indicated that $\mathrm{NM}$ training in individual sports is more effective than CONV, as it leads to improvements in balance control. Possibly, these improvements could increase the performance of artistic gymnasts in the balance beam apparatus and could hypothetically modify the incidence of injuries. However, this assumption must be tested in future research related to the identification of risk factors and prevention of sports injuries.

This research has limitations related to the selection for convenience of the participants because of the small number of gymnasts in order to obtain an adequate sample size. Furthermore, considering only the balance control variable, it is not really known which is the best training to generate global changes in the performance of gymnasts. Future research could consider balance platforms or test batteries that can quantify the balance control in gymnastic positions typical of the sport technique or of the different devices used in competitions. Finally, other essential training methods in gymnastics based on flexibility, strength, and 
power could be compared, and it could even be taken into account how the development of balance control is affected by other factors, such as the emotional state and muscle fatigue of the subjects [34, 35].

\section{Conclusions}

NM training results in significant improvement of balance control compared with CONV and SEBT in female artistic gymnasts. In this context, this study contributes to the comparison among different training methods focused on improving balance control, which is important for a sports improvement approach that leads to optimal performance in artistic gymnastics.

\section{Disclosure statement}

No author has any financial interest or received any financial benefit from this research.

\section{Conflict of interest}

The authors state no conflict of interest.

\section{References}

1. Desai N, Vance DD, Rosenwasser MP, Ahmad CS. Artistic gymnastics injuries; epidemiology, evaluation, and treatment. J Am Acad Orthop Surg. 2019;27(13):459467; doi: 10.5435/JAAOS-D-18-00147.

2. Mkaouer B, Hammoudi-Nassib S, Amara S, Chaabène H. Evaluating the physical and basic gymnastics skills assessment for talent identification in men's artistic gymnastics proposed by the International Gymnastics Federation. Biol Sport. 2018;35(4):383-392; doi: 10.5114/biolsport.2018.78059.

3. Fédération Internationale de Gymnastique. Individual apparatus World Cup Rules 2017-2020 in Artistic Gymnastics. 2016. Available from: https://www.gymnastics.sport/publicdir/rules/files/es_WAG\%20 CoP\%202017-2020.pdf.

4. Sobera A, Sobera M, Kleszyk K. Foot and ankle deformity in young acrobatic and artistic gymnasts. Hum Mov. 2015;16(3):130-136; doi: 10.1515/humo-2015-0034.

5. Hart E, Meehan WP $3^{\text {rd }}$, Bae DS, d'Hemecourt P, Stracciolini A. The young injured gymnast: a literature review and discussion. Curr Sports Med Rep. 2018;17(11): 366-375; doi: 10.1249/JSR.0000000000000536.

6. Panjan A, Sarabon N. Review of methods for the evaluation of human body balance. Sport Sci Rev. 2010; 19(5-6):131-163; doi: 10.2478/v10237-011-0036-5.

7. Guimaraes-Ribeiro D, Hernández-Suárez M, RodríguezRuiz D, García-Manso JM. Effect of systematic rhythmic gymnastics training on postural control of young girls [in Spanish]. Rev Andal Med Deporte. 2015;8(2): 54-60; doi: 10.1016/j.ramd.2014.11.001.
8. Fasuyi FO, Adegoke BOA. Contribution of some physical characteristics to unipedal non-dominant lower limb balance among footballers. Hum Mov. 2018; 19(4):71-78; doi: 10.5114/hm.2018.77328.

9. Faquin BS, Coelho Candido CR, Mochizuki L, Alves Okazaki VH. Effect of visual and vestibular information on spatial perception on gait. Hum Mov. 2018;19(2):39-45; doi: 10.5114/hm.2018.74058.

10. Fink H, Hofmann D, Scholtz D. Age group development and high competition programme for men's artistic gymnastics [in Spanish]. Lausanne: Fédération Internationale de Gymnastique; 2021. Available from: http: //www.gymnastics.sport/site/pages/education/agegroup-mag-manual-s.pdf.

11. Ganesh GS, Chhabra D, Pattnaik M, Mohanty P, Patel R, Mrityunjay K. Effect of trunk muscles training using a star excursion balance test grid on strength, endurance and disability in persons with chronic low back pain. J Back Musculoskelet Rehabil. 2015;28(3):521530; doi: 10.3233/BMR-140551.

12. Hewett TE, Patterno MV, Myer GD. Strategies for enhancing proprioception and neuromuscular control of the knee. Clin Orthop Relat Res. 2002;402:76-94; doi: 10.1097/01.blo.0000026962.51742.99.

13. Hübscher M, Zech A, Pfeifer K, Hänsel F, Vogt L, Banzer W. Neuromuscular training for sports injury prevention: a systematic review. Med Sci Sports Exerc. 2010;42(3):413-421; doi: 10.1249/MSS.0b013e3181b $88 \mathrm{~d} 37$.

14. Olmsted LC, Carcia CR, Hertel J, Shultz SJ. Efficacy of the Star Excursion Balance Tests in detecting reach deficits in subjects with chronic ankle instability. J Athl Train. 2002;37(4):501-506.

15. Bonato M, Benis R, La Torre A. Neuromuscular training reduces lower limb injuries in elite female basketball players. A cluster randomized controlled trial. Scand J Med Sci Sports. 2018;28(4):1451-1460; doi: 10.1111/sms.13034.

16. Hewett TE, Lindenfeld TN, Riccobene JV, Noyes FR. The effect of neuromuscular training on the incidence of knee injury in female athletes: a prospective study. Am J Sports Med. 1999;27(6):699-706; doi: 10.1177/ 03635465990270060301.

17. Moeskops S, Read PJ, Oliver JL, Lloyd RS. Individual responses to an 8-week neuromuscular training intervention in trained pre-pubescent female artistic gymnasts. Sports. 2018;6(4):128; doi: 10.3390/sports6040128.

18. Fullam K, Caulfield B, Coughlan GF, Delahunt E. Kinematic analysis of selected reach directions of the Star Excursion Balance Test compared with the Y-Balance Test. J Sport Rehabil. 2014;23(1):27-35; doi: 10.1123/JSR.2012-0114.

19. Coughlan GF, Fullam K, Delahunt E, Gissane C, Caulfield BM. A comparison between performance on selected directions of the Star Excursion Balance Test and the Y Balance Test. J Athl Train. 2012;47(4):366371; doi: 10.4085/1062-6050-47.4.03. 
G. Mendez-Rebolledo, Y. Olcese-Farias, D. Brown-Villegas, Balance training in artistic gymnasts

20. Root H, Marshall AN, Thatcher A, Snyder Valier AR, Valovich McLeod TC, Curtis Bay R. Sport specialization and fitness and functional task performance among youth competitive gymnasts. J Athl Train. 2019;54(10): 1095-1104; doi: 10.4085/1062-6050-397-18.

21. Benis R, Bonato M, La Torre A. Elite female basketball players' body-weight neuromuscular training and performance on the Y-Balance Test. J Athl Train. 2016; 51(9):688-695; doi: 10.4085/1062-6050-51.12.03.

22. Willis BW, Razu S, Baggett K, Jahandar A, Gray AD, Skubic M, et al. Sex differences in frontal and transverse plane hip and knee kinematics during the modified Star Excursion Balance Test. Hum Mov. 2017;18(3): 26-33; doi: 10.1515/humo-2017-0028.

23. Gribble PA, Hertel J, Denegar CR, Buckley WE. The effects of fatigue and chronic ankle instability on dynamic postural control. J Athl Train. 2004;39(4):321329; doi: 10.3844/PISP.2010.22.26.

24. Da Silva TC, Felippe LA, Carregaro RL, Christofoletti G. Postural instability in subjects with Parkinson's disease undergoing different sensory pitfalls. Hum Mov. 2017;18(4):55-60; doi: 10.1515/humo-2017-0031.

25. Butler RJ, Southers C, Gorman PP, Kiesel KB, Plisky PJ. Differences in soccer players' dynamic balance across levels of competition. J Athl Train. 2012;47(6):616-620; doi: 10.4085/1062-6050-47.5.14.

26. Vuillerme N, Danion F, Marin L, Boyadjian A, Prieur JM, Weise I, et al. The effect of expertise in gymnastics on postural control. NeurosciLett. 2001;303(2):8386; doi: 10.1016/S0304-3940(01)01722-0.

27. Carrick FR, Oggero E, Pagnacco G, Brock JB, Arikan T. Posturographic testing and motor learning predictability in gymnasts. Disabil Rehabil. 2007;29(24):18811889; doi: 10.1080/09638280601141335.

28. Bressel E, Yonker JC, Kras J, Heath EM. Comparison of static and dynamic balance in female collegiate soccer, basketball, and gymnastics athletes. J Athl Train. 2007; 42(1):42-46.

29. Riemann BL, Myers JB, Lephart SM. Comparison of the ankle, knee, hip, and trunk corrective action shown during single-leg stance on firm, foam, and multiaxial surfaces. Arch Phys Med Rehabil. 2003;84(1):90-95; doi: 10.1053/apmr.2003.50004.

30. Winter DA. Biomechanics and motor control of human movement. New York: John Wiley \& Sons; 1990.

31. Sabin MJ, Ebersole KT, Martindale AR, Price JW, Broglio SP. Balance performance in male and female collegiate basketball athletes: influence of testing surface. J Strength Cond Res. 2010;24(8):2073-2078; doi: 10.1519/JSC.0b013e3181ddae13.

32. Michalski Peres M, Cecchini L, Pacheco I, Moré Pacheco A. Effects of proprioceptive training on the stability of the ankle in volleyball players [in Portuguese]. Rev Bras Med Esporte. 2014;20(2):146-150; doi: 10.1590/1517-86922014200202046.

33. Vitale JA, La Torre A, Banfi G, Bonato M. Effects of an 8 -week body-weight neuromuscular training on dynamic balance and vertical jump performances in elite junior skiing athletes: a randomized controlled trial. J Strength Cond Res. 2018;32(4):911-920; doi: 10.1519/JSC.000 0000000002478.

34. Cetin N, Bayramoglu M, Aytar A, Surenkok O, Yemisci OU. Effects of lower-extremity and trunk muscle fatigue on balance. Open Sports Med J. 2008;2(1):16-22; doi: 10.2174/1874387000802010016.

35. Buatois S, Gauchard GC, Aubry C, Benetos A, Perrin P. Current physical activity improves balance control during sensory conflicting conditions in older adults. Int J Sports Med. 2007;28(1):53-58; doi: 10.1055/s-2006924054. 